\title{
The Production of Itaconic Acid and Tetronic Acids with Respect to the Growth Cycle of Penicillium charlesii
}

\author{
By A. P. MALONEY* And MARGARET M. ATTWOOD \\ Department of Microbiology, University of Sheffield, Sheffield SI $2 T N$
}

(Received 2I January 1976)

INTRODUCTION

Clutterbuck et al. (1934) reported that the metabolic products of the mould Penicillium charlesii G. Smith grown on glucose as the carbon and energy source were two polysaccharides and six organic acids - carolic, carlosic, carlinic, carolinic, verticillic and ramigenic acids. Subsequent work showed that verticillic acid and ramigenic acid were artefacts arising from the reaction between a further acid product, $\gamma$-methyltetronic acid, and the acetone used in the extraction procedure (Clutterbuck, Raistrick \& Reuter, 1935). Later workers studying the organic acid products have failed to agree as to the number and type of metabolites produced. Bentley, Bhate \& Keil (1962) and R. Bentley (personal communication) failed to detect all the tetronic acids originally reported; whilst Lybing \& Reio (1958) showed that, at least under certain conditions, itaconic acid was produced. The data reported in this paper support the claim of Bentley et al. (1962), in that only three tetronic acids were detected. The time of initiation suggested that these occurred as secondary metabolic products. Itaconic acid was also detected in the culture medium but was only formed during the primary growth phase.

\section{METHODS}

Organism and growth conditions. Isolates of Penicillium charlesii G. Smith IMI40232 were obtained from the Commonwealth Mycological Institute, Kew. Stock cultures from single spore subcultures were maintained on slopes of $4 \%(w / v)$ Oxoid potato dextrose agar in screw-capped bottles ( $15 \mathrm{ml}$ ). Cultures were grown at $25^{\circ} \mathrm{C}$ until the surface was covered with conidia ( 3 to 4 weeks) and then used as a source of fungal spores. The medium used for the growth experiments was that described by Clutterbuck et al. (I935). Erlenmeyer flasks ( $(00 \mathrm{ml})$ containing medium $(20 \mathrm{ml}$ ) adjusted to $\mathrm{pH} 4.5$ were inoculated with a suspension of conidia in sterile distilled water containing the neutral detergent Teepol L $(0.01 \%(w / v)$; $\mathrm{BDH})$, to give a final concentration of $7.5 \times 10^{5}$ conidia $\mathrm{ml}^{-1}$. The cultures were incubated at $24 \pm \mathrm{I}^{\circ} \mathrm{C}$ on a rotary shaker operating at $150 \mathrm{rev} . \mathrm{min}^{-1}$.

Sampling methods. Sample flasks were taken at intervals throughout the culture period. The mycelium was harvested by filtration and the medium removed for analysis. After washing, the mycelium was dried to a constant weight at $110{ }^{\circ} \mathrm{C}$.

Analytical methods. Glucose carbon was measured using the glucose oxidase-peroxidase method of Bergmeyer \& Bernt (I965). Nitrate was reduced to nitrite in the presence of zinc, and the nitrite was measured by the method of Nicholas \& Nason (1957). Tetronic acids were detected and estimated by measuring the extinction of the medium filtrate at $265 \mathrm{~nm}$

\footnotetext{
* Present address: Beecham Pharmaceuticals (U.K. division), Worthing, Wes! Sussex.
} 
<smiles>CC1OC(=O)C=C1O</smiles>

$\gamma$-Methyltetronic acid<smiles>CCCC1=C(O)C(CO)OC1=O</smiles>

Carlosic acid<smiles>CC1OC(=O)C(C(=O)CCCO)=C1O</smiles>

Carolic acid<smiles>O=C(O)CC(=O)O</smiles>

Itaconic acid

Fig. I. The constitution of the metabolites detected.

under alkaline conditions (Bentley et al., 1962) or at $274 \mathrm{~nm}$ under acid conditions (Spencer, I96I).

Extraction of metabolites. After harvesting the mycelium, the culture filtrate and the mycelium washings were bulked. The metabolites were extracted by a modification of the method described by Bentley et al. (1962). The bulked filtrate and mycelium washings were reduced in volume in vacuo ( $10 \mathrm{ml}$ ), absolute alcohol was added, and the precipitated polysaccharide collected. The alcohol precipitation was repeated to ensure complete precipitation of all the polysaccharide. The filtrate was acidified by adding distilled water $(\mathrm{I} 6 \mathrm{ml})$ followed by concentrated hydrochloric acid (sp.gr. I $\cdot 18 ; 2 \cdot 0 \mathrm{ml})$. The acidified solution was then extracted with ethyl acetate $(3 \times 50 \mathrm{ml})$ and the non-aqueous fraction bulked and evaporated to dryness in vacuo. The residue was taken up in distilled water and then extracted, initially with diethyl ether $(4 \times 15 \mathrm{ml})$ and then with chloroform $(2 \times 20 \mathrm{ml})$, as described by Bentley et al. (1962). The introduction of the ethyl acetate extraction resulted in better separation of the products by thin-layer chromatography.

Identification of the metabolites. Carolic acid was identified by the methods used by Bentley et al. (1962). Carlosic acid was extracted from the ether fraction and its identity determined by (i) its elution effluent volume from a silicic-acid column with chloroform and butanol (Marvel \& Rands, I950) as reported by Lybing \& Reio (1958); and (ii) its spectrum in alkaline conditions. Methyltetronic acid was extracted from the ether fraction as a mercury salt, followed by treatment with hydrogen sulphide and extraction with ether; its melting point agreed with reported data (Clutterbuck et al., 1935). Itaconic acid was identified by co-chromatography with a standard prepared from commercially available itaconic acid (BDH). The purified compounds were kept as standards for co-chromatography used for routine identification of the compounds in other experiments.

Separation of metabolites. The metabolites in the ether and chloroform fractions were routinely separated and identified by (i) direct chromatography with standards on cellulose thin-layer plates, or (ii) separation on an anion-exchange column and identification by thin-layer chromatography.

Thin-layer chromatography. Metabolites (100 $\mu \mathrm{g}$ ) were taken up in ethanol (5 to $10 \mu \mathrm{l}$ ) 
and applied to cellulose thin-layer plates $(20 \times 20 \times 0.1 \mathrm{~mm})$. Solvent systems used were: ethyl methyl ketone/acetone/water $/ 90 \%(\mathrm{w} / \mathrm{v})$ formic acid $(80: 4: 12: 2$, by vol.); diethy lether/ $90 \%(\mathrm{w} / \mathrm{v})$ formic acid/water (7:2:I, by vol.). After development, the plates were sprayed with $0.04 \%$ bromocresol green in $95 \%(\mathrm{v} / \mathrm{v})$ ethanol. The acids appeared as yellow spots on a blue background.

Anion-exchange separation. Metabolites (25 mg) were added to the top of a $25 \times \mathrm{I} \cdot 5 \mathrm{~cm}$ column of AG I-X8 anion exchange resin in the formate form (BioRad). The column was eluted with a continuous gradient of formic acid (o to $6 \mathrm{M})$. Fractions $(2.5 \mathrm{ml})$ were analysed for tetronic acids by measuring the extinction at $274 \mathrm{~nm}$. To detect any other acidic metabolite, including itaconic acid, each fraction was titrated against I M-sodium hydroxide and the volume required to neutralize it was recorded. Using a similar column, but without the addition of metabolites, the same formic acid gradient was titrated to obtain a base line for the elution pattern. The metabolites in each peak were identified by reducing the peak volume to dryness, dissolving the residue in ethanol, and separating the metabolites on thinlayer plates as described.

Radioactive labelling. Radioactive chemicals were purchased from The Radiochemical Centre, Amersham, Buckinghamshire. Flasks containing growth medium were inoculated and incubated for 3 days. Then either $\mathrm{D}-\left[\mathrm{U}-{ }^{14} \mathrm{C}\right]$ glucose, sodium [U-14 $\left.\mathrm{C}\right]$ acetate or sodium $\left[2,3-{ }^{14} \mathrm{C}\right]-$ succinate $(0 . \mathrm{I} \mathrm{ml}$ containing Io $\mu \mathrm{Ci})$ was added to a series of flasks. After another 4 days incubation, the mycelium was harvested and the culture filtrate extracted as described. At each step, samples were taken and analysed for the presence of radioactivity using standard liquid scintillation counting techniques. Any fraction containing a significant amount of radioactivity was analysed by direct thin-layer chromatography or by anion-exchange chromatography followed by thin-layer chromatography as described. After development of the plates, but before visualization of the spots, autoradiograms were made. The radioactive spots were identified by alignment of the autoradiograms with the visualized spots on the thin-layer plates.

\section{RESULTS AND DISCUSSION}

\section{The growth cycle and tetronic acid production}

Using the growth conditions described, an active primary growth phase (3 days) was followed by a secondary metabolic production phase ( 4 to 5 days). Tetronic acids were detected at the end of the primary phase of growth. The initial metabolite production appeared to be correlated with the exhaustion of the nitrogen supply in the medium, and the cessation of production with the exhaustion of glucose carbon from the medium (Table I). This correlation was substantiated when the organism was grown in the standard medium containing $0.1 \%(\mathrm{w} / \mathrm{v})$ potassium nitrate instead of $0.2 \%(\mathrm{w} / \mathrm{v})$ : tetronic acid production began on day 2 rather than on day 4 . If the glucose concentration in the standard medium was decreased from $5 \%(w / v)$ to $2 \%(w / v)$, the time of initiation of tetronic acid production was the same as with the standard medium, but the total yield of metabolites was reduced. The $\mathrm{pH}$ of the medium showed a characteristic variation with time. It increased until the end of the primary growth phase and then decreased until a value of $2 \cdot 0$ to 3.0 was attained. This value remained constant throughout the period of metabolite production unless the mycelium lysed, in which case the $\mathrm{pH}$ increased to around $7 \cdot 5$.

\section{Metabolic products}

The metabolites produced were extracted from the medium into the ether and chloroform fractions. Thin-layer chromatographic procedures, using the two solvent systems described, 
Table I. Growth and tetronic acid production by Penicillium charlesii

$\begin{array}{cccccc}\begin{array}{c}\text { Time } \\ \text { (days) }\end{array} & \begin{array}{c}\text { Dry weight } \\ \left(\mathrm{mg} \mathrm{ml}^{-1}\right)\end{array} & \begin{array}{c}\text { Tetronic acid } \\ \text { produced } \\ \left(\mathrm{mg} \mathrm{ml}^{-1}\right)\end{array} & \begin{array}{c}\text { Glucose } \\ \left(\mathrm{mg} \mathrm{ml}^{-1}\right)\end{array} & \begin{array}{c}\text { Nitrate } \\ \left(\mathrm{mg} \mathrm{ml}^{-1}\right)\end{array} & \mathrm{pH} \\ 0 & 0 & 0 & 50 & 0 \cdot 12 & 4 \cdot 5 \\ 2 & 0 \cdot 8 & 0 & 42 \cdot 3 & 0 \cdot 07 & 5 \cdot 0 \\ 3 & 7 \cdot 3 & 0 & 30 \cdot 6 & 0 \cdot 03 & 5 \cdot 8 \\ 4 & \mathbf{8 \cdot 5} & \mathrm{I} \cdot 0 & 21 \cdot 8 & 0 & 3 \cdot 2 \\ 5 & 9 \cdot 3 & 2 \cdot 1 & 12 \cdot 0 & 0 & 2 \cdot 8 \\ 6 & 9 \cdot 9 & 3 \cdot 4 & 5 \cdot 6 & 0 & 2 \cdot 7 \\ 7 & 10 \cdot 1 & 4 \cdot 4 & 3 \cdot 5 & 0 & 2 \cdot 5 \\ 8 & 10 \cdot 3 & 5 \cdot 1 & 0 \cdot 8 & 0 & 2 \cdot 5 \\ \text { I0 } & 10 \cdot 2 & 5 \cdot 3 & 0 & 0 & 2 \cdot 6 \\ \text { I2 } & 10 \cdot 2 & 5 \cdot 2 & 0 & 0 & 2 \cdot 5\end{array}$

separated four metabolites which were identified by co-chromatography as itaconic acid, $\gamma$-methyltetronic acid, carolic acid and carlosic acid (Fig. I). Separation of the metabolites from the medium filtrate by anion-exchange chromatography before thin-layer chromatography did not reveal any other acid metabolite. Four acid peaks were eluted from the column and each peak contained one product only: itaconic acid, carolic acid, carlosic acid and $\gamma$-methyltetronic acid.

It was possible that other metabolites were produced but were not present in large enough amounts to be detected by the above methods. To increase the sensitivity of the screening procedure for detecting metabolites, radioactive incorporation experiments were carried out. Bentley et al. (1962) reported significant incorporation of ${ }^{14} \mathrm{C}$ from glucose, succinic acid and acetate into tetronic acids. Therefore the fungus was grown until no more nitrogen could be detected in the medium (Table I), and then incubated with either $\left[{ }^{14} \mathrm{C}\right]$ glucose, $\left[{ }^{14} \mathrm{C}\right]$ acetate or $\left[{ }^{14} \mathrm{C}\right]$ succinate. Radioactivity was associated with the mycelium, the ethanol precipitate, the ether and chloroform fractions and the final aqueous solution. Using thinlayer chromatograms and autoradiograms, it was shown that the ether and chloroform fractions contained three metabolite spots. Each spot contained radioactive carbon and was formed from one compound only. These were identified as $\gamma$-methyltetronic acid, carolic acid and carlosic acid. Neither radioactive itaconic acid nor any other labelled metabolite was detected. The radioactivity in the final aqueous layer was due to radioactive substrate, whilst the ${ }^{14} \mathrm{C}$ in the ethanol precipitate was associated with polysaccharide.

\section{Production of metabolites with time}

Because of the unexpected failure to detect radioactively labelled itaconic acid, the production of metabolites was monitored daily by direct thin-layer chromatography of the separated medium fractions. Itaconic acid was the only metabolite produced during the primary growth phase. Once this phase terminated, no further production of itaconic acid was detected but the production of tetronic acid began. The amount of tetronic acids produced increased with time until a maximum yield was obtained when the glucose was exhausted (Table I). The small amount of itaconic acid present was either further metabolized or masked on the thin-layer plates by the large amounts of $\gamma$-methyltetronic acid. The present data confirm the observations of Bentley et al. (1962) rather than the report of Clutterbuck et al. (1935), in that three rather than four tetronic acids were detected. Furthermore, the radioactive incorporation experiments, originally designed to increase the sensitivity of the metabolite screening procedure, did not result in the detection of new metabolites, but, instead, failed to detect itaconic acid shown in earlier experiments to be produced by 
Penicillium charlesii. It has been demonstrated that this failurewas not due to the biosynthesis of itaconic acid from compounds other than glucose or a metabolic product of glucose, but to the fact that itaconic acid is only produced during the primary growth phase of the fungus, and so the biosynthesis of itaconic acid had terminated before the radioactive carbon was added. As tetronic acid production was initiated after the cessation of primary growth, radioactive tetronic acids were detected. This production of itaconic acid only during the primary growth phase could explain the finding of Lybing \& Reio (1958) that itaconic acid is only formed under certain conditions. Thus the formation of itaconic acid is an example of the production of a primary metabolite, whereas the biosynthesis of tetronic acids shows the characteristics associated with the synthesis of secondary metabolite products.

A.P.M. wishes to acknowledge the receipt of a Batchelor Fellowship.

\section{REFERENCES}

Bentley, R., Bhate, D. S. \& KeIL, J. G. (1962). Tetronic acid biosynthesis in moulds. I. Formation of carlosic and carolic acids in Penicillium charlesii. Journal of Biological Chemistry 237, 859-866.

Bergmeyer, H.-U. \& BerNT, E. (1965). Determination of glucose with glucose oxidase and peroxidase. In Methods of Enzymatic Analysis, pp. 123-I30. Edited by H.-U. Bergmeyer. London \& New York: Academic Press.

Clutterbuck, P. W., Haworth, W. N., Raistrick, H., Smith, G. \& Stacey, M. (I934). Studies in the biochemistry of micro-organisms. XXXVI. The metabolic products of Penicillium charlesii G. Smith. Biochemical Journal 20, 94-I 10.

Clutterbuck, P. W., Raistrick, H. \& Reuter, F. (1935). Studies in the biochemistry of micro-organisms. XLV. The metabolic products of Penicillium charlesii G. Smith. IV: Methyltetronic acid, with observations on the formation and structure of ramigenic and verticillic acid. Biochemical Journal 29, I 300-1 309.

LyBING, S. \& ReIO, L. (1958). Degradation of ${ }^{14} \mathrm{C}$-labelled carolic and carlosic acids from Penicillium charlesii G. Smith. Acta chemica scandinavica I2, 1575-1 584 .

MARVel, C. S. \& RANDS, R. D. (1950). Separation of organic acids. Journal of the American Chemical Society 72, 2642-2646.

Nicholas, D. J. D. \& Nason, A. (1957). Determination of nitrate and nitrite. In Methods in Enzymology vol. 3, pp. 98I-984. Edited by S. P. Colowick and N. O. Kaplan. New York: Academic Press.

SPENCER, N. (1961). Paper chromatographic and electrophoretic separation and identification of some naturally occurring tetronic acids. Journal of Chromatography 6, 498-504. 